JGG 2021;69:296-298

doi: $10.36150 / 2499-6564-N 465$
Clinical Geriatrics - Reviews

\section{Care networks, integrated care models, and primary care}

\author{
Gerardo Medea \\ Italian College of General Practice and Primary Care, Brescia, Italy; Italian Society of General Medicine \\ and Primary Care, Florence, Italy
}

\section{RECOMMENDATIONS}

A. Treatment of geriatric DM patients should aim to improve quality of life and prevent deterioration of functional status, hospitalization and emergency room visits.

B. A well-established healthcare network is needed to ensure continuity of care. A multidisciplinary team (e.g., GPs, nurses, diabetologists, geriatricians, other specialists) should provide integrated care and, where possible, keep a shared repository of systematically collected, clearly defined clinical data including: communication, regulations, quality and safety requirements for care pathways, monitoring system and process and outcome indicators, role, skills, and tasks of the professionals involved, each of whom must act according to the patient's care needs (i.e. level of complexity), which vary over time.

C. The patient's care plan should be primarily managed by the GP (clinical manager), as DM is only one of different coexisting conditions and other factors (psychological and social) that influence a patient's clinical complexity, especially in geriatric patients. Diabetologists and other specialists have a role in defining and implementing patient care plans. In particularly complex cases, diabetics centers should take the main responsibility for conducting regular, frequent check-ups on the patient.

Correspondence

Gerardo Medea

General Practitioner, via della Filanda 4, 25011

Calcinato (BS), Italy

E-mail: medea.gerardo@alice.it

How to cite this article: Medea G. Care networks, integrated care models, and primary care. Journal of Gerontology and Geriatrics 2021;69:296-298. https://doi. org/10.36150/2499-6564-N465

(C) Copyright by Società Italiana

di Gerontologia e Geriatria (SIGG)

\section{(c) (1) $(9)$}

OPEN ACCESS

This is an open access article distributed in accordance with the CC-BY-NC-ND (Creative Commons Attribution-NonCommercial-NoDerivatives 4.0 International) license. The article can be used by giving appropriate credit and mentioning the license, but only for non-commercial purposes and only in the original version. For further information: https://creativecommons.org/licenses/by-nc-nd/4.0/deed.en
D. Frail patients need special attention, as they have a high risk of experiencing a decline in quality of care (and, consequently, an increased risk of complications and hospitalization), and they require comprehensive geriatric assessment. GPs can benefit from consulting a geriatrician, especially about issues such as deprescribing, individualization of care plans, and prioritizing interventions.

\section{STRENGTH OF THE RECOMMENDATIONS}

The quality of the evidence is low. Recommendations are supported by published evidence and best practice (supported by expert opinion).

\section{SUPPORTING EVIDENCE}

See appendix. 


\section{AREAS OF UNCERTAINTY AND FUTURE PERSPECTIVES}

There are no studies in the literature that have assessed the effectiveness (e.g., reducing hospitalizations and emergency room visits) of care models specifically designed for geriatric DM patients. Fragmented care systems, lack of clinical information, duplication of medical services, and heterogeneity, particularly in the types of interventions and outcomes are major obstacles to delivering optimal care to DM patients. Improvement of clinical care and outreach in diabetic geriatric patients can be achieved mainly by enhancing organization (both in primary care and specialize diabetes centers) to obtain regular, planned follow-ups using centralized computer monitoring systems or nurses who keep in regular contact with the patient.

\section{APPENDIX}

Treatment of geriatric DM patients should aim to improve quality of life and prevent events that could lead to a loss of functioning, which can cause hospitalizations and emergency room visits. A meta-analysis demonstrated that Comprehensive Geriatric Assessment is essential for managing patients with frailty, to define treatment plans and ensure the best quality of life possible as well as increase survival ${ }^{1}$.

Chronic care models (CCM) have shown moderate efficacy in improving the quality of DM care ${ }^{2}$. Multifaceted professional interventions could enhance the performance of health professionals for managing DM patients ${ }^{3}$. Organizational interventions that incentive regular, planned follow-ups and review of patients' clinical status and therapy (using central computerized tracking systems or nurses who regularly contact the patient) can also improve DM management. Management of DM patients requires a care system that has a network of different carers and healthcare professionals working in interdisciplinary teams ${ }^{4}$. Integrated care involving both primary care clinics and diabetes centers is effective for managing DM geriatric patients in terms of improving quality of care ${ }^{5}$, reducing emergency room visits and increasing visits to GPs and primary care nurses ${ }^{6}$, reducing hospitalizations for diabetes complications ${ }^{7}$, lowering the risk of cardiovascular events including strokes ${ }^{8}$, and reducing mortality for all causes and cardiovascular events ${ }^{8,9}$.

An Italian observational study ${ }^{10}$ showed that compared to DM patients cared for by their GP only or by diabetologists only, those receiving integrated care had lower mortality. The authors concluded that, after an initial expert evaluation at a specialized diabetes center, low-risk
DM patients can be managed by primary care physicians as part of an integrated care approach managed by the GP and based on the specialist's clinical recommendations, with subsequent referrals to the specialist if and when the clinical condition requires it ${ }^{10}$. Another observational study ${ }^{11}$ on DM patients demonstrated that patients who were managed with a Chronic Care Model significantly improved adherence to the followup program and reduced cardiovascular complications (IRR 1,11; IC 95\% 1.04-1.18). A protective effect was also observed for neurological complications, cardioand cerebro-vascular complications, and mortality.

Chronic care models and integrated care approaches complement each other as they are organized, integrated, proactive, population-oriented systems, which place an informed/educated patient at the center of the whole system playing an active role in the management of their disease. Emphasis should, therefore, be placed on continuity of care through greater integration and coordination between levels of care and active patient involvement during the course of care.

The IGEA (Integrazione Gestione E Assistenza) project ${ }^{12}$ has specifically addressed the integrated management of DM patients in Italy (2012), concluding that there is considerable heterogeneity, particularly in the types of interventions and outcomes considered. Thus, it is not possible to accurately compare integrated and conventional care models, particularly in sub-populations of patients in relation to relevant outcomes. However, a systematic review and meta-analysis ${ }^{13,14}$ showed that integrated care leads to a small improvement in glycemic control compared to conventional treatment programs.

The Italian PND (Piano Nazionale Diabete) ${ }^{15}$ strongly emphasizes that the best care for DM patients includes regional and national assistance that is provided in an integrated way by all players in the network. Within the care network, each player needs to follow the appropriate care pathway according to the patient's clinical complexity.

The 2010 Political and Strategic Guidance Document for appropriate DM care by AMD (Associazione Medici Diabetologi), SIMG (Società Italiana di Medicina Generale) and SID (Società Italiana di Diabetologia) ${ }^{16}$ highlighted the need for a care network system supported by a multi-specialized and multidisciplinary integrated care model that can implement patient care plans. They identified seven classes of care intensity according to specific clinical characteristics, planned interventions, the healthcare professionals responsible for care coordination, and standards for monitoring and quality indicators. In particular, Class 5 (stable DM patients, with good metabolic compensation, without current complications, being monitored for various cardiovascular risk 
factors,) and Class 6 (DM patients with multiple chronic comorbidities and reduced independence) are those who can primarily be followed by GPs in a primary care setting.

\section{Ethical consideration}

None.

\section{Acknowledgement}

None.

Funding

None.

\section{Conflict of interest}

Roche diagnostic (consultant)

\section{References}

1 Stuck AE, Siu AL, Wieland GD, et al. Comprehensive geriatric assessment: a meta-analysis of controlled trials. Lancet 1993;342:1032-1036. https://doi. org/10.1016/0140-6736(93)92884-v

2 Stellefson M, Dipnarine K, Stopka C. The chronic care model and diabetes management in US primary care settings: a systematic review. Prev Chronic Dis 2013;10:E26. https://doi.org/10.5888/pcd10.120180

3 Renders CM, Valk GD, Griffin S, et al. Interventions to improve the management of diabetes mellitus in primary care, outpatient and community settings. Cochrane Database Syst Rev 2001;2000:CD001481. https://doi. org/10.1002/14651858.cd001481

4 Rossi MCE, Nicolucci A, Arcangeli A, et al. Baseline quality-of-care data from a quality-improvement program implemented by a network of diabetes outpatient clinics. Diabetes Care 2008;31:2166-2168. https://doi.org/10.2337/ dc08-0469

5 Gnavi R, Picariello R, la Karaghiosoff L, et al. Determinants of quality in diabetes care process: the population-based Torino Study. Diabetes Care 2009;32:1986-1892. https:// doi.org/10.2337/dc09-0647

6 Mateo-Abad M, Fullaondo A, Merino M, et al. Impact assessment of an innovative integrated care model for older complex patients with multimorbidity: the CareWell Project. Int J Integr Care 2020;20:8. https://doi.org/10.5334/ ijic. 4711
7 Zhang J, Donald M, Baxter KA, et al. Impact of an integrated model of care on potentially preventable hospitalizations for people with Type 2 diabetes mellitus. Diabet Med 2015;32:872-880. https://doi.org/10.1111/dme.12705

8 Kornelius E, Chiou J-Y, Yang Y-S, et al. The diabetes shared care program and risks of cardiovascular events in type 2 diabetes. Am J Med 2015;128:977-985.e3. https:// doi.org/10.1016/j.amjmed.2015.03.025

9 Giorda CB. The role of the care model in modifying prognosis in diabetes. Nutr Metab Cardiovasc Dis 2013;23:11 16. https://doi.org/10.1016/j.numecd.2012.07.001

10 Baldo V, Lombardi S, Cocchio S, et al. Diabetes outcomes within integrated healthcare management programs. Prim Care Diabetes 2015;9:54-59. https://doi.org/10.1016/j. pcd.2014.03.005

11 Profili F, Bellini I, Zuppiroli A, et al. Changes in diabetes care introduced by a Chronic Care Model-based programme in Tuscany: a 4-year cohort study. Eur J Public Health 2017;27:14-19. https://doi.org/10.1093/eurpub/ckw181

12 Istituto Superiore di Sanità - Centro Nazionale di Epidemiologia, Sorveglianza e Promozione della Salute. Sistema IGEA: integrazione, gestione e assistenza per la malattia diabetica (https://www.epicentro.iss.it/igea).

13 Norris SL, Lau J, Smith SJ, et al. Self-management education for adults with type 2 diabetes: a meta-analysis of the effect on glycemic control. Diabetes Care 2002;25:11591171. https://doi.org/10.2337/diacare.25.7.1159

14 Knight K, Badamgarav E, Henning JM, et al. A systematic review of diabetes disease management programs. Am J Manag Care 2005;11:242-250.

15 Ministero della Salute, DG Programmazione Sanitaria, Commissione Nazionale Diabete. Piano sulla malattia diabetica (https://www.salute.gov.it/imgs/C_17_pubblicazioni_1885_allegato.pdf).

16 Medical Diabetologist Association, Italian Society of General Medicine and Primary Care, Italian Society of Diabetology. Documento di indirizzo politico e strategico per la buona assistenza alle persone con diabete. Published online 2010 (https://www.aemmedi.it/files/Linee-guida_ Raccomandazioni/2010/2010-documento_indirizzo.pdf).

\section{This statement is: \\ Recommendation (supported by published evidence) $\otimes$ Best practice (supported by expert opinion)}

Quality of the evidence (in the case of recommendation):

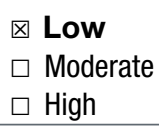

